OPEN ACCESS

Edited by:

Arjan C. Lankester,

Leiden University, Netherlands

Reviewed by:

Dmitry Balashov,

Dmitry Rogachev National Research Center of Pediatric Hematology, Oncology and Immunology, Russia Krzysztof Kalwak,

Wroclaw Medical University, Poland

*Correspondence:

Peter Shaw

peter.shaw@health.nsw.gov.au

Specialty section:

This article was submitted to

Pediatric Immunology,

a section of the journal

Frontiers in Pediatrics

Received: 19 July 2019 Accepted: 07 October 2019 Published: 06 November 2019

Citation:

Shaw P, Shizuru J, Hoenig M and Veys $P$ (2019) Conditioning

Perspectives for Primary

Immunodeficiency Stem Cell Transplants. Front. Pediatr. 7:434. doi: 10.3389/fped.2019.00434

\section{Conditioning Perspectives for Primary Immunodeficiency Stem Cell Transplants}

\author{
Peter Shaw ${ }^{1 *}$, Judith Shizuru ${ }^{2}$, Manfred Hoenig ${ }^{3}$ and Paul Veys ${ }^{4}$ \\ on behalf of the IEWP-EBMT
}

${ }^{1}$ Children's Hospital at Westmead, Sydney, NSW, Australia, ${ }^{2}$ Departments of Medicine and Pediatrics, Stanford University, Stanford, CA, United States, ${ }^{3}$ Klinik für Kinder- und Jugendmedizin, Universitätsklinikum Ulm, Ulm, Germany, ${ }^{4}$ Great Ormond Street Hospital for Children NHS Foundation Trust, London, United Kingdom

The majority of children undergoing Hematopoietic Stem cell Transplantation (HSCT) require conditioning therapy to make space and prevent rejection of the donor stem cells. The exception is certain children with Severe Combined immune deficiency, who have limited or no ability to reject the donor graft. Transplant conditioning is associated with significant morbidity and mortality from both direct toxic effects of chemotherapy as well as opportunistic infections associated with profound immunosuppression. The ultimate goal of transplant practice is to achieve sufficient engraftment of donor cells to correct the underlying disease with minimal short- and long-term toxicity to the recipient. Traditional combinations, such as busulfan and cyclophosphamide, achieve a high rate of full donor engraftment, but are associated with significant acute transplant-related-mortality and late effects such as infertility. Less "intensive" approaches, such as combinations of treosulfan or melphalan with fludarabine, are less toxic, but may be associated with rejection or low level chimerism requiring the need for re-transplantation. The major benefit of these novel approaches, however, which we hope will be realized in the decades to come, may be the preservation of fertility. Future approaches look to replace chemotherapy with non-toxic antibody conditioning. The lessons learnt in refining conditioning for HSCT are likely to be equally applicable to gene therapy protocols for the same diseases.

Keywords: conditioning, hematopoietic stem cell transplant (HSCT), chemotherapy, immunotherapy, immunoablation

\section{KEY POINTS}

- Conditioning is required for the majority of children with non-malignant diseases.

- Some children with severe combined immune deficiency require little or no conditioning-but this usually only corrects $\mathrm{T}$ cell function.

- Mixed chimerism may indicate that re-transplantation may be required.

- Less intensive conditioning is:

$\circ$ Less toxic.

- Associated with more mixed chimerism and may require further procedures.

- May allow long term preservation of fertility. 


\section{INTRODUCTION}

With the exception of some children with severe combined immunodeficiencies (SCID, see review on SCID), all patients who undergo allogeneic Hematopoietic Stem cell Transplantation (HSCT) require therapy prior to receipt of the graft. This conditioning therapy plays a vital role in allowing engraftment of new Hematopoietic progenitor cells (HPC) in the patient. These new HPC can correct some, or occasionally all, of the manifestations of a non-malignant disease.

\section{THE NEED FOR CONDITIONING}

In the original publications of HSCT for malignant disease, intensive high-dose combinations of irradiation and chemotherapy were used to eradicate resistant leukemia and ablate the bone marrow. These myeloablative combinations (MAC) achieved prolonged aplasia, and were associated with full donor chimerism (DC). However, such therapy is associated with a significant burden of early and late toxicities, making MAC less suitable for older patients, or those with significant co-morbidities. This led to the concept of reduced intensity (RIC) regimens, which are defined as regimens containing reduced doses of myeloablative drugs (or radiotherapy), which are therefore less likely to achieve marrow ablation and more likely to produce mixed chimerism (MC). For the vast majority of HSCTs, namely older adults with malignant disease, the balance between MAC and RIC is a clear trade off: more transplant-related mortality (TRM) is seen with MAC, and more relapse with RIC; these 2 often counter-balancing each other. Multiple attempts to define RIC in terms of specific drug doses were made during 2006-2009, however, there is a spectrum of conditioning and it is preferable to define truly nonmyeloablative or minimally intensive conditioning protocols (MIC) where the initial neutrophil recovery is frequently recipient, MAC protocols which mostly achieve sustained full donor chimerism, and then RIC protocols which comprise all those in-between (1). The spectrum of conditioning is shown in Figure 1.

\section{CONDITIONING, CHIMERISM, AND CONSIDERATIONS IN NON-MALIGNANT DISEASES}

Full myeloablative conditioning is most likely to achieve full donor chimerism. In non-malignant disease, correction of the underlying disease may be achievable with stable mixed chimerism. It appears that a level of $20-30 \%$ donor chimerism in the diseased lineage can achieve correction of the phenotype in, for example, CGD or SCD. But achieving stable mixed donor chimerism reliably with a specific conditioning regimen has been challenging, and $10-20 \%$ of patients will require a further procedure such as DLI or 2nd HSCT. This is because patients with non-malignant diseases, who have often had no prior therapy, are more able to reject a graft unless adequate conditioning has been given. In a cohort of over 600 patients with non-malignant disease having unrelated transplants, the cumulative incidence of primary or secondary graft failure at 1 year was $17 \%$ (2). Risk factors for graft failure were HLA mismatch and use of RIC.

In contrast, patients with primary immune deficiency (PID), with a partial or complete inability to reject a graft, can achieve MC or full DC with no conditioning or RIC. The first successful allogeneic transplantation reported was performed without conditioning (or graft-versus-host disease prophylaxis) in a patient with X-linked Severe Combined Immunodeficiency (SCID) in 1968 (3). Although engraftment of peripheral Tlymphocytes alone is reliably achieved without conditioning in children with SCID, and this is sufficient to at least transiently allow control of infections and survival, the omission of conditioning also has risks. This was observed in this first patient: by 3 months after administration of the unmanipulated graft from the HLA-identical sibling, the patient developed trilineage aplasia and needed a boost of donor stem cells for hematological reconstitution (4). This graft-versus-marrow (GvM) effect is caused by the donor T-lymphocytes targeting recipient bone marrow cells, leading to a clinical picture of aplastic anemia. This effect is normally hidden by the more obvious marrow depleting effects by chemotherapeutic agents. This effect is more relevant with less intense conditioning regimens, and can be best observed in SCID patients, but is abolished if the graft is also T-cell depleted. Factors that can impact on the outcome of transplant are shown in Table 1.

\section{TYPES OF CONDITIONING IN CLINICAL USE}

For decades, a combination of myeloablative doses of busulfan $\mathrm{Bu}$ and cyclophosphamide was used for many children with a wide variety of non-malignant diseases. Its efficacy, in reliably achieving full DC, is not questioned. However, the profile of toxicity, in particular with endothelial injury, most often manifested as veno-occlusive disease (VOD) means we have continued to look for alternatives.

Reducing the Bu dose and increasing the immunosuppression, e.g., by replacing cyclophosphamide with fludarabine (mirroring the RIC approach), has produced good results (5), particularly in CGD. Retrospective comparisons have shown a similar rate of survival with BuFlu and $\mathrm{BuCy}$ (6), but some physicians have been troubled by the increased MC seen with Bu Flu in contrast to $\mathrm{BuCy}$.

Substituting treosulfan (Treo) for $\mathrm{Bu}$ is undoubtedly less toxic, with a low rate of VOD. Although the term "reduced toxicity" was first used to describe a Treo-based regimen (7), the combination of Treo Flu does not consistently achieve full DC and so is perhaps better labeled as RIC (See Figure 1). Treo may have a further advantage over $\mathrm{Bu}$, for instance in young children with SCID, in that it does not cross the blood brain barrier and may therefore have less neurotoxic properties. On the other hand, for children with MPS1 and MLD, engraftment of brain microglial cells is dependent on $\mathrm{Bu}$ (at high doses) for ablation, and is superior to Treo or irradiation $(8,9)$. This is one example where MAC may be preferable to RIC in the non-malignant 


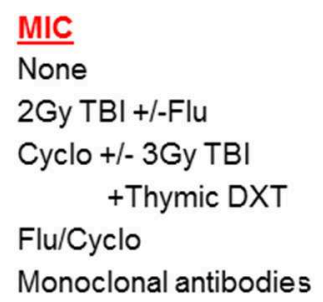

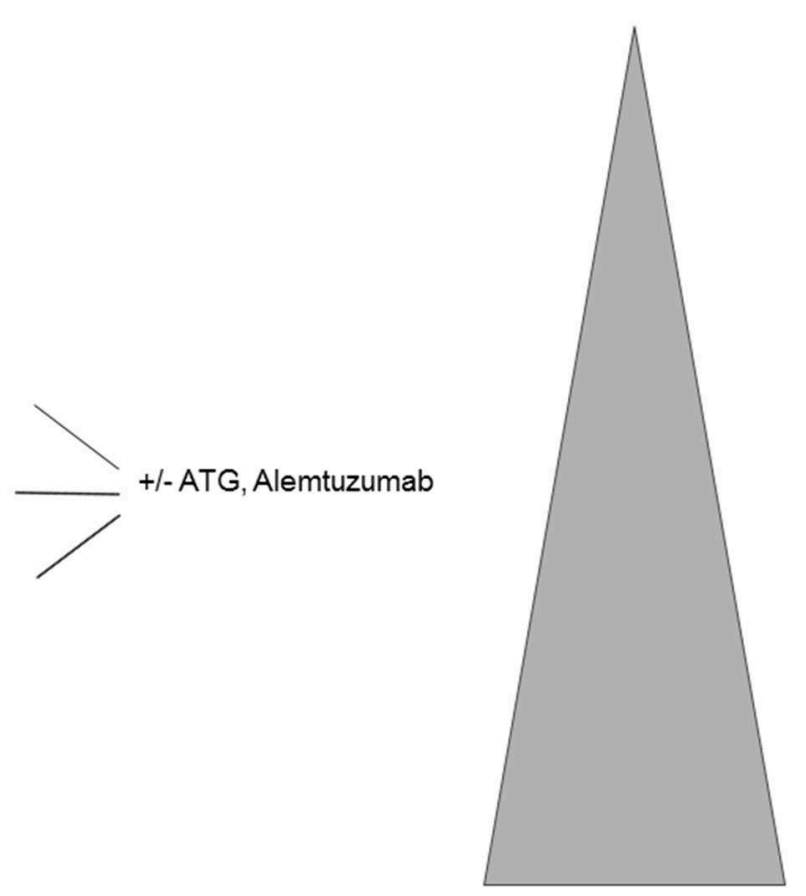

FIGURE 1 | Spectrum of conditioning used.

setting. Although Treo Flu can produce adequate levels of MC in children with PID, including CGD and WAS (10-12), for those with more active marrow function, the frequency of $\mathrm{MC}$ can be reduced by adding a third agent, thiotepa, and this 3 drug combination is usually myeloablative (13). In addition, there are diseases where more complete DC may be necessary to control some aspects of the disease, such as the auto-immunity that is seen in WAS (14) and a variety of other monogenic disease, many of which are collectively referred to as Tregopathies (15).

The combination of Flu with Melphalan was the first widely used RIC protocol in PID (16). However, its reduced myeloablation often leads to excessive MC (17), although when followed by DLI achieves excellent results in HLH (18).

\section{THE ROLE OF GRAFT-VERSUS-HOST DISEASE PROPHYLAXIS AND SEROTHERAPY}

In addition to the conditioning therapy given to allow engraftment of donor cells, it is also important to prevent allogeneic T-lymphocytes from the graft reacting against the donor (or host), which causes graft-versus-host disease (GvHD).

\section{Ex-vivo T-Cell Depletion (TCD)}

Some of the earliest HSCT were done using mismatched donors, often haploidentical parents. Here the risk of GvHD is so high that methods were developed to deplete the $\mathrm{T}$ cells from the graft, so reducing the risk of GvHD. Over the years, the techniques have become more sophisticated, from ex-vivo Sheep red cell rosetting and soybean lectin (19), to CD3/19 depletion
TABLE 1 | Factors that may affect outcome of transplant.

\begin{tabular}{ll}
$\begin{array}{l}\text { Relevant factors for therapeutic } \\
\text { strategy }\end{array}$ & With an influence on... \\
\hline Genetic disease, PID & $\begin{array}{l}\text { Ability to reject a graft } \\
\text { Cellular lineages to be corrected (myeloid } \\
\text { engraftment needed?) }\end{array}$ \\
& $\begin{array}{l}\text { Intensity of tolerable conditioning } \\
\text { Intensity of tolerable conditioning }\end{array}$ \\
Clinical condition (infections, organ & \\
damage) & HLA match \\
Donor availability & rejection \\
& GvHD \\
& Graft-versus-marrow effect \\
& Quantity and quality of cellular \\
(sub-)populations in the graft \\
Stem cell source (bone marrow, \\
GBSCs, CB) & Graft-versus-marrow effect \\
& GvHD \\
Graft manipulation (in vitro or in-vivo) & Graft-versus-marrow effect \\
T-cell depletion) &
\end{tabular}

and now TCR $\alpha \beta$-depletion (20). Although TCD also depletes cells that may be important in controlling residual leukemia, in immune deficient patients this is much less important. However, the depletion of cells that can control opportunistic infections, particularly viral infections, does contribute to morbidity and mortality after these mismatched procedures.

\section{In vivo-TCD}

A variety of drugs are used to deplete $\mathrm{T}$ cells pre and post transplant. 


\section{Serotherapy}

Serotherapy is used, as part of conditioning therapy, to deplete function of specific host immune cells, which are able to reject the graft. As these agents have long half-lives, they persist after the graft is infused and so, by depleting allogeneic Tlymphocytes from the graft, can reduce GvHD (21). Two main types of "sero"therapy are in use: polyclonal preparations of anti-thymocyte globulin (ATG) from immunized rabbits or horses and a humanized monoclonal antibody targeting CD52 (Alemtuzumab). It is well-known that different brands of ATG clear at different rates, so impacting on subsequent rates of $\mathrm{GvHD}$, infection and immune reconstitution (22). In the absence of any prospective head-to-head study, a retrospective study showed that immunological reconstitution was more rapid after the use of ATG (Thymoglobubulin ${ }^{\circledR}$ ) $10 \mathrm{mg} / \mathrm{kg}$ in comparison to alemtuzumab $(1 \mathrm{mg} / \mathrm{kg})$, as expected from the longer halflive of the latter (23). In recent years important novel aspects beyond dosage have been considered in more detailed studies. As the therapeutic antibodies persist over several days, the timing of the administration before or even after transfusion of the transplant has an impact on the rate of GvHD and the delay in the reconstitution of donor T-lymphocytes, as shown for umbilical cord blood transplantation (24). Beyond dosage and timing, the abundance of target structures, namely T-lymphocytes has been shown to have fundamental impacts on the pharmacokinetics and the effects of ATG (25). Similar studies with Alemtuzumab, in the context of Flu MLP, have shown the expected relationship of higher peritransplant serum-levels of alemtuzumab being associated with less GvHD, slower immune reconstitution and more mixed chimerism (26). Pharmacokinetic (PK) targeting of serotherapy in conditioning is probably as desirable as PK monitoring of chemotherapy and, particularly in RIC, might achieve maximum GvM with minimal GvHD.

A variety of other drugs are used to inhibit $\mathrm{T}$ cell activation post-HSCT, such as ciclosporin and Tacrolimus. Certain chemotherapy drugs are used widely to target cells proliferating in response to allo-antigens, such as methotrexate and, most notably in the past few years, posttransplant cyclosphosphamide. The powerful effect of 2 days of cyclophosphamide given in the first few days after haploidentical HSCT has made this technique readily available to centers that do not have the laboratory skills, resources and money to support the complex procedures such as $\operatorname{TCR} \alpha \beta$-depletion. Admittedly, this is more widely used in malignant disease and hematological diseases but has been used in immune deficiencies as well (27).

\section{LONG TERM CONSEQUENCES OF CONDITIONING}

For long term survivors of HSCT, some long term toxicities relate to the conditioning used (see review on "long term outcome and immune function after haematopoietic stem cell transplantation for primary immunodeficiency"). In general, the more myeloablative combinations are associated with gonadal failure and infertility; whereas the RIC combinations may be associated with preservation of these important long term toxicities. Currently, long term follow up data for children treated with Treo are lacking, but early data looks promising (28).

The development of malignancy is another major long term consequence of transplant, But the majority of these appear to be secondary malignancies in patients transplanted for malignant disease, with the exception of Fanconi anemia.

\section{EMERGING TYPES OF CONDITIONING FOR THE (NEAR) FUTURE}

As mentioned above, for the sick infant with newly diagnosed SCID, an unconditioned graft may be required, to achieve some T-lymphocyte function and control of infection, and then allow an older child in better shape to tolerate a conditioned graft and achieve a better functioning (donor) immune system. With the adoption of newborn screening for SCID, younger, well infants are being diagnosed earlier, at an age where the use of conventional chemotherapy is less studied and with diagnoses (such as Artemis) where the adverse consequences of chemotherapy are well-known (29). To achieve the desired outcome of conditioning with minimal toxicity, development of targeted treatment with monoclonal antibodies and other biologic agents is underway.

Preclinical studies identified CD45 (30) and CD117 (31, 32) as targets suitable for antibody mediated depletion of host hematopoietic cells. CD45, also known as the leukocyte common antigen (LCA), is expressed on all hematolymphoid cells. Because CD45 is expressed on the spectrum of primitive to mature blood cells, targeting this molecule is desirable if a single agent can safely achieve both myelo- and lymphoablation. Different forms of anti-CD45 agents have been tested including "naked" unconjugated, radio-labeled, and toxin-conjugated CD45 antibodies. Conjugation of antibodies to radio-isotopes or cytotoxic agents capitalizes on the ability of the antibodies to deliver toxic payloads to specific cell populations with the potential for more complete target cell elimination as compared to the unconjugated versions. However, the risks of the conjugates may limit the applicability of these agents to only select disorders.

A synergistic combination of two unconjugated rat antihuman CD45 antibodies has been tested in two clinical studies. A Phase 1 dose escalation study used these mAbs in patients with hematologic malignancies that received standard conditioning (33) and as part of reduced-intensity conditioning regimen for congenital immunodeficiencies, in conjunction with anti-lymphocyte agents (34). The regimen was well-tolerated and high-level donor chimerism was achieved. However, the contribution of the lytic anti-CD45 mAb treatment in the context of these other agents remains to be further clarified.

Clinical testing of radioisotope-labeled anti-CD45 mAbs are in the advanced phase in adults with myeloid disorders, and second generation agents continue to be developed (35) CD45 antibody-drug conjugates (ADC) have been shown promise in preclinical models evidenced by their ability to efficiently deplete immune cells in the periphery and HSCs in the bone 
marrow (36). Development of clinical grade CD45-ADC is currently underway.

Antibodies that target the cell surface receptor CD117 can also effectively clear host HSC niches. CD117 is a receptor tyrosine kinase expressed on the surface of HSC and early hematopoietic progenitors. Interaction of CD117 with its ligand, stem cell factor (SCF), provides signals necessary for HSC survival, proliferation, and differentiation. Treatment of mice with anti-CD117 mAbs results in transient depletion of HSC with return of normal blood formation within 2 weeks of antibody administration (37). This window of depletion is sufficient to permit donor cell engraftment with minimal to no off target effects.

A humanized anti-CD117 mAb, AMG 191 has been developed and is currently undergoing testing as sole conditioning for patients with SCID. Large animal studies support the safety and efficacy of this agent in depleting HSC (38). Early data from the Phase 1 dose escalation trial show proof-of-concept that targeting CD117 with biologic agents may provide a strategy for safely replacing and/or augmenting the myeloablative component of conditioning (39). Even at the lowest dose tested sustained donor HSC engraftment has been observed as evidenced by long-term myeloid chimerism, and generation of nascent B and

\section{REFERENCES}

1. Bacigalupo A, Ballen K, Rizzo D, Giralt S, Lazarus H, Ho V, et al. Defining the intensity of conditioning regimens: working definitions. Biol Blood Marrow Transplant. (2009) 15:1628-33. doi: 10.1016/j.bbmt.2009.07.004

2. Horan J, Wang T, Haagenson M, Spellman SR, Dehn J, Eapen M, et al. Evaluation of HLA matching in unrelated hematopoietic stem cell transplantation for nonmalignant disorders. Blood. (2012) 120:2918-24. doi: 10.1182/blood-2012-03-417758

3. Gatti RA, Meuwissen HJ, Allen HD, Hong R, Good RA. Immunological reconstitution of sex-linked lymphopenic immunological deficiency. Lancet. (1968) 2:1366-9. doi: 10.1016/S0140-6736(68)92673-1

4. Meuwissen HJ, Gatti RA, Terasaki PI, Hong R, Good RA. Treatment of lymphopenic hypogammaglobulinemia and bonemarrow aplasia by transplantation of allogeneic marrow. Crucial role of histocompatiility matching. N Engl J Med. (1969) 281:691-7. doi: 10.1056/NEJM196909252811302

5. Gungor T, Teira P, Slatter M, Stussi G, Stepensky P, Moshous D, et al. Reduced-intensity conditioning and HLA-matched haemopoietic stem-cell transplantation in patients with chronic granulomatous disease: a prospective multicentre study. Lancet. (2014) 383:436-48. doi: 10.1016/S0140-6736(13)62069-3

6. Harris AC, Boelens JJ, Ahn KW, Fei M, Abraham A, Artz A, Dvorak C, et al. Comparison of pediatric allogeneic transplant outcomes using myeloablative busulfan with cyclophosphamide or fludarabine. Blood Adv. (2018) 2:1198206. doi: 10.1182/bloodadvances.2018016956

7. Casper J, Knauf W, Kiefer T, Wolff D, Steiner B, Hammer U, et al. Treosulfan and fludarabine: a new toxicity-reduced conditioning regimen for allogeneic hematopoietic stem cell transplantation. Blood. (2004) 103:725-31. doi: 10.1182/blood-2002-11-3615

8. Capotondo A, Milazzo R, Politi LS, Quattrini A, Palini A, Plati T, et al. Brain conditioning is instrumental for successful microglia reconstitution following hematopoietic stem cell transplantation. Proc Natl Acad Sci USA. (2012) 109:15018-23. doi: 10.1073/pnas.1205858109

9. Wilkinson FL, Sergijenko A, Langford-Smith KJ, Malinowska M, Wynn RF, Bigger BW. Busulfan conditioning enhances engraftment of hematopoietic donor-derived cells in the brain compared with irradiation. Mol Ther. (2013) 21:868-76. doi: $10.1038 / \mathrm{mt} .2013 .29$
T-lymphocytes. No toxicities related to the AMG 191 were noted, including no evidence of myelosuppression.

Pre-clinical studies have focused on increasing the niche clearing potency of the naked anti-CD117 antibodies. The combination of a second $\mathrm{mAb}$ directed against the macrophage checkpoint inhibitor, CD47, with an anti-CD117 mAb demonstrated marked increase in myeloablation and donor cell engraftment compared to the CD117 mAb alone (31). Other strategies which show promise include ADC-conjugates of anti-CD117 mAbs $(36,37)$ and the combined use of anti-CD117 with low dose radiation (40).

\section{AUTHOR CONTRIBUTIONS}

All authors listed have made a substantial, direct and intellectual contribution to the work, and approved it for publication.

\section{FUNDING}

This work was supported by the California Institute for Regenerative Medicine, DR2A-05365 and the H.L. Snyder Medical Foundation (JS).

10. Slatter MA, Rao K, Amrolia P, Flood T, Abinun M, Hambleton S, et al. Treosulfan-based conditioning regimens for hematopoietic stem cell transplantation in children with primary immunodeficiency: United Kingdom experience. Blood. (2011) 117:4367-75. doi: 10.1182/blood-2010-10-312082

11. Morillo-Gutierrez B, Beier R, Rao K, Burroughs L, Schulz A, Ewins AM, et al. Treosulfan-based conditioning for allogeneic HSCT in children with chronic granulomatous disease: a multicenter experience. Blood. (2016) 128:440-8. doi: 10.1182/blood-2016-03-704015

12. Slatter MA, Rao K, Abd Hamid IJ, Nademi Z, Chiesa R, Elfeky R, Pearce MS, et al. Treosulfan and fludarabine conditioning for hematopoietic stem cell transplantation in children with primary immunodeficiency: UK experience. Biol Blood Marrow Transplant. (2018) 24:529-36. doi: 10.1016/j.bbmt.2017.11.009

13. Shah RM, Elfeky R, Nademi Z, Qasim W, Amrolia P, Chiesa R, et al. Tcell receptor $\alpha \beta^{+}$and $\mathrm{CD} 19^{+}$cell-depleted haploidentical and mismatched hematopoietic stem cell transplantation in primary immune deficiency. $J$ Allergy Clin Immunol. (2018) 141:1417-26.e1. doi: 10.1016/j.jaci.2017.07.008

14. Moratto D, Giliani S, Bonfim C, Mazzolari E, Fischer A, Ochs HD, Cant AJ, et al. Long-term outcome and lineage-specific chimerism in 194 patients with Wiskott-Aldrich syndrome treated by hematopoietic cell transplantation in the period 1980-2009: an international collaborative study. Blood. (2011) 118:1675-84. doi: 10.1182/blood-2010-11-319376

15. Cepika AM, Sato Y, Liu JM, Uyeda MJ, Bacchetta R, Roncarolo MG. Tregopathies: Monogenic diseases resulting in regulatory T-cell deficiency. $J$ Allergy Clin Immunol. (2018) 142:1679-95. doi: 10.1016/j.jaci.2018.10.026

16. Rao K, Amrolia PJ, Jones A, Cale CM, Naik P, King D, et al. Improved survival after unrelated donor bone marrow transplantation in children with primary immunodeficiency using a reduced-intensity conditioning regimen. Blood. (2005) 105:879-85. doi: 10.1182/blood-2004-0 3-0960

17. Rao K, Adams S, Qasim W, Allwood Z, Worth A, Silva J, Lucchini G, et al. Effect of stem cell source on long-term chimerism and event-free survival in children with primary immunodeficiency disorders after fludarabine and melphalan conditioning regimen. J Allergy Clin Immunol. (2016) 138:115260. doi: 10.1016/j.jaci.2016.01.053

18. Marsh RA, Rao MB, Gefen A, Bellman D, Mehta PA, Khandelwal P, et al. Experience with alemtuzumab, fludarabine, and melphalan reducedintensity conditioning hematopoietic cell transplantation in patients with 
nonmalignant diseases reveals good outcomes and that the risk of mixed chimerism depends on underlying disease, stem cell source, and alemtuzumab regimen. Biol Blood Marrow Transplant. (2015) 21:1460-70. doi: 10.1016/j.bbmt.2015.04.009

19. Reisner Y, Kapoor N, Kirkpatrick D, Pollack MS, Cunningham-Rundles S, Dupont B, et al. Transplantation for severe combined immunodeficiency with HLA-A,B,D,DR incompatible parental marrow cells fractionated by soybean agglutinin and sheep red blood cells. Blood. (1983) 61:341-8. doi: 10.1182/blood.V61.2.341.bloodjournal612341

20. Bertaina A, Merli P, Rutella S, Pagliara D, Bernardo ME, Masetti R, et al. HLA-haploidentical stem cell transplantation after removal of alphabeta ${ }^{+} \mathrm{T}$ and B cells in children with nonmalignant disorders. Blood. (2014) 124:822-6. doi: 10.1182/blood-2014-03-563817

21. Ali R, Ramdial J, Algaze S, Beitinjaneh A. The role of anti-thymocyte globulin or alemtuzumab-based serotherapy in the prophylaxis and management of graft-versus-host disease. Biomedicines. (2017) 5:E67. doi: 10.3390/biomedicines5040067

22. Oostenbrink LVE, Jol-van der Zijde CM, Kielsen K, Jansen-Hoogendijk AM, Ifversen M, Muller KG, et al. Differential elimination of anti-thymocyte globulin of fresenius and genzyme impacts T-cell reconstitution after hematopoietic stem cell transplantation. Front Immunol. (2019) 10:315. doi: 10.3389/fimmu.2019.00315

23. Willemsen L, Jol-van der Zijde CM, Admiraal R, Putter H, Jansen-Hoogendijk $\mathrm{AM}$, Ostaijen-Ten Dam MM, et al. Impact of serotherapy on immune reconstitution and survival outcomes after stem cell transplantations in children: thymoglobulin versus alemtuzumab. Biol Blood Marrow Transplant. (2015) 21:473-82. doi: 10.1016/j.bbmt.2014.11.674

24. Lindemans CA, Chiesa R, Amrolia PJ, Rao K, Nikolajeva O, de Wildt A, et al. Impact of thymoglobulin prior to pediatric unrelated umbilical cord blood transplantation on immune reconstitution and clinical outcome. Blood. (2014) 123:126-32. doi: 10.1182/blood-2013-05-502385

25. Admiraal R, van Kesteren C, Jol-van der Zijde CM, Lankester AC, Bierings $\mathrm{MB}$, Egberts TC, et al. Association between anti-thymocyte globulin exposure and $\mathrm{CD}^{+}$immune reconstitution in paediatric haemopoietic cell transplantation: a multicentre, retrospective pharmacodynamic cohort analysis. Lancet Haematol. (2015) 2:e194-203. doi: 10.1016/S2352-3026(15)00045-9

26. Marsh RA, Lane A, Mehta PA, Neumeier L, Jodele S, Davies SM, et al. Alemtuzumab levels impact acute GVHD, mixed chimerism, and lymphocyte recovery following alemtuzumab, fludarabine, and melphalan RIC HCT. Blood. (2016) 127:503-12. doi: 10.1182/blood-2015-07-659672

27. Klein OR, Chen AR, Gamper C, Loeb D, Zambidis E, Llosa N, et al. Alternative-donor hematopoietic stem cell transplantation with posttransplantation cyclophosphamide for nonmalignant disorders. Biol Blood Marrow Transplant. (2016) 22:895-901. doi: 10.1016/j.bbmt.2016.02.001

28. Faraci M, Diesch T, Labopin M, Dalissier A, Lankester A, Gennery A,et al. Gonadal function after busulfan compared with treosulfan in children and adolescents undergoing allogeneic hematopoietic stem cell transplant. Biol Blood Marrow Transplant. (2019) 25:1786-91. doi: 10.1016/j.bbmt.2019.05.005

29. Schuetz C, Neven B, Dvorak CC, Leroy S, Ege MJ, Pannicke U, et al. SCID patients with ARTEMIS vs RAG deficiencies following HCT: increased risk of late toxicity in ARTEMIS-deficient SCID. Blood. (2014) 123:281-9. doi: 10.1182/blood-2013-01-476432
30. Matthews DC, Appelbaum FR, Eary JF, Hui TE, Fisher DR, Martin PJ, et al. Radiolabeled anti-CD45 monoclonal antibodies target lymphohematopoietic tissue in the macaque. Blood. (1991) 78:1864-74.

31. Chhabra A, Ring AM, Weiskopf K, Schnorr PJ, Gordon S, Le AC, et al. Hematopoietic stem cell transplantation in immunocompetent hosts without radiation or chemotherapy. Sci Transl Med. (2016) 8:351ra105. doi: 10.1126/scitranslmed.aae0501

32. Czechowicz A, Kraft D, Weissman IL, Bhattacharya D. Efficient transplantation via antibody-based clearance of hematopoietic stem cell niches. Science. (2007) 318:1296-9. doi: 10.1126/science.1149726

33. Krance RA, Kuehnle I, Rill DR, Mei Z, Pinetta C, Evans W, et al. Hematopoietic and immunomodulatory effects of lytic CD45 monoclonal antibodies in patients with hematologic malignancy. Biol Blood Marrow Transplant. (2003) 9:273-81. doi: 10.1053/bbmt.2003.50024

34. Straathof KC, Rao K, Eyrich M, Hale G, Bird P, Berrie E, et al. Haemopoietic stem-cell transplantation with antibody-based minimalintensity conditioning: a phase $1 / 2$ study. Lancet. (2009) 374:912-20. doi: 10.1016/S0140-6736(09)60945-4

35. Orozco JJ, Zeller J, Pagel JM. Radiolabeled antibodies directed at CD45 for conditioning prior to allogeneic transplantation in acute myeloid leukemia and myelodysplastic syndrome. Ther Adv Hematol. (2012) 3:5-16. doi: 10.1177/2040620711422265

36. Palchaudhuri R, Saez B, Hoggatt J, Schajnovitz A, Sykes DB, Tate TA, et al. Non-genotoxic conditioning for hematopoietic stem cell transplantation using a hematopoietic-cell-specific internalizing immunotoxin. Nat Biotechnol. (2016) 34:738-45. doi: 10.1038/nbt.3584

37. Czechowicz A, Palchaudhuri R, Scheck A, Hu Y, Hoggatt J, Saez B, et al. Selective hematopoietic stem cell ablation using CD117-antibody-drugconjugates enables safe and effective transplantation with immunity preservation. Nat Commun. (2019) 10:617. doi: 10.1038/s41467-01808201-x

38. Kwon HS, Logan AC, Chhabra A, Pang WW, Czechowicz A, Tate K, et al. Anti-human CD117 antibody-mediated bone marrow niche clearance in non-human primates and humanized NSG mice. Blood. (2019) 133:2104-8. doi: 10.1182/blood-2018-06-853879

39. Agarwal R, Dvorak CC, Prohaska S, Long-Boyle J, Kwon H-S, Brown JM, et al. Toxicity-free hematopoietic stem cell engraftment achieved with antiCD117 monoclonal antibody conditioning. Biol Blood Marrow Transplant. (2019) 25:S92. doi: 10.1016/j.bbmt.2018.12.172

40. Xue X, Pech NK, Shelley WC, Srour EF, Yoder MC, Dinauer MC. Antibody targeting KIT as pretransplantation conditioning in immunocompetent mice. Blood. (2010) 116:5419-22. doi: 10.1182/blood-2010-07-295949

Conflict of Interest: The authors declare that the research was conducted in the absence of any commercial or financial relationships that could be construed as a potential conflict of interest.

Copyright (c) 2019 Shaw, Shizuru, Hoenig and Veys. This is an open-access article distributed under the terms of the Creative Commons Attribution License (CC BY). The use, distribution or reproduction in other forums is permitted, provided the original author(s) and the copyright owner(s) are credited and that the original publication in this journal is cited, in accordance with accepted academic practice. No use, distribution or reproduction is permitted which does not comply with these terms. 